\title{
South African Pharmaceutical Prices: An International Price Comparison
}

\section{George G Djolov ${ }^{1}$}

\section{School of Economic and Business Sciences, University of the Witwatersrand}

\begin{abstract}
A major presumption underlying the current debate on pharmaceutical prices in South Africa is that South African medicines are priced at levels out of line with comparable products in other countries. This paper presents some empirical evidence in an attempt to ascertain the validity of these presumptions. The results provide little support for the view that South African prices are in need of controls over and above those already existing through competition. The evidence reveals that recent calls and public policy proposals for parallel importation and its variant reference pricing are misplaced. To put forward such proposals without taking account of existing empirical knowledge for policy (or legislative) making purposes is a less than optimal approach.
\end{abstract}

JEL C 130, I 180

\section{INTRODUCTION}

A major presumption underlying the current debate on pharmaceutical prices in South Africa is that South African medicines are priced at levels out of line with comparable products in other countries. To contain medicine costs Act 90 of 1997 ( $\$ 15 \mathrm{C}$ and $\$ 22 \mathrm{G})$ proposes the use of parallel importation or its variant reference pricing. Parallel importation refers to the policy of allowing the importation of the same drugs as those available in South Africa if they can be obtained cheaper, i.e. at a lower price, elsewhere. A variant of parallel trade is reference pricing, which is the policy where the price set for a drug in a given country is the average of the lowest prices of the same drug in other countries.

This paper presents some empirical evidence in an attempt to ascertain the validity of the presumptions guiding these public policy proposals. First, some thoughts are presented about the intrinsic difficulties of carrying out price comparisons between countries. Second, the results of two pricing studies, one for the private sector and the other for the public sector are presented. Here it may be instructive to note that the South African healthcare market splits into 
two separate sectors or markets, i.e. the private and the public. The private sector caters for those with income and medical cover and the public sector, which is administered by the State, caters for the poor (or indigent). The State purchases drugs for the public sector using the COMED tender system. The manufacturer able to meet a tender at the lowest or specified price is awarded the tender for the supply of a particular medicine or medicines. The study for the private sector presents a comparison between prices in South Africa and seven other countries. The study for the public sector presents a comparison between tender prices in South Africa and those obtainable through international competitive bidding, i.e. international tendering.

\section{INTERNATIONAL PRICE COMPARISON CAVEATS}

The discussion here is based on a synthesis of that offered by Danzon (2000: 5659), Nesbitt (2000: 14-25 of chapter 2), and Reekie (1997: 20-26).

International price comparisons of pharmaceuticals are subject to a number of difficulties. Indeed the number and nature of the reservations imply that they should only be used with extreme care. Many would argue they should not be used at all. First, identical or analogous products must be compared. Most countries have several hundred, even thousands of drugs on sale. Many are not available elsewhere. The products selected for comparison must not only be available to compare but they should be important in their respective markets. This is not necessarily easy to achieve since not all products are available in every country. Further, the mix of leading products varies by disease incidence, medical convention and legal framework. These impact on product usage and even on the presentation of the product (e.g. vaccines and tablets may differ in usage between countries and hence so too, may the relative prices). Not only must the compared products all be of similar commercial importance on the demand side, that condition should also exist on the supply side. If products vary in importance to the marketing firm, then price patterns may differ. Similarly, if the marketing firm is a licensee, this also impacts on pricing behaviour, as does the nature of any (unknown) royalty agreement. Moreover, questions must be asked as to the level in the distribution chain at which the prices are compared. Are the prices affected by the nature of that institutional arrangement? Manufacturer prices are the basis from which final consumer prices derive, but intermediaries vary in importance country-by-country in the costs they impose or save on any transaction. Some intermediaries are passive; others are active buyers seeking out best prices. This in turn raises the issue of whether list prices or transaction prices are used. Most data sources use list prices, and surveys, which use transaction prices -which are more meaningful-,are high cost tasks (and neither buyer nor seller may be willing to 
divulge the information). Should the price be at pack level? (Most products are sold in several alternative pack sizes). If so, which pack? Should it be at unit level? And if so, which unit? (Units vary for the same product, e.g. $125 \mathrm{mg}$ or $375 \mathrm{mg}$ ). Which form should be compared, oral solid or injectable, or some other? Should it rather be at cost per daily treatment, or cost per prescription (covering several days)? After all different drugs require different quantities to be consumed daily, or have different numbers of days' treatment in a regimen. To select any one criterion, of course, implies selection from a "most commonly adopted" criterion in country A, which may be inappropriate in country B.

In a world of exchange rate movements, at what date is the comparison to be made? A 10 per cent movement in a currency immediately alters any computed results by that amount.

If non-branded (generic ${ }^{2}$ ) drugs are excluded from a study, but they have a significant market share in any given country, then their exclusion will bias comparisons. The bias could make the drug bill in the country with a small generic share appear to be relatively lower than it is in reality. The country with the high generic share would have its price level over-stated (since generics are generally cheaper than branded products).

One further reservation is that in any study prices of drugs sold for ambulatory care should not be compared with those of drugs sold to bulk-buying institutions such as hospitals. In the case of South Africa, this reservation must be extended to the exclusion of the entire State sector where drugs are purchased in bulk and by tender. The relevant comparison in our first study is the prices of drugs in the South African private sector.

Before proceeding with the results and the methodology of the study a note is in order concerning the type of price studies whose methodology may centre on comparing a basket of high selling (by value) products in one country with the same products in another country irrespective of the selling status of these products there. Precaution must be exercised with such studies given their methodology is highly likely to produce biased results. This can be explained with reference to the construction of the demand curve. If the products are highselling items in the one country (country A) but are low-selling items in the other (country B), prices in the former instance would be low, whereas in the latter instance they would be high. Thus if one is to construct price ratios (weighted by volumetric market share) the choice of the country which assumes the numerator determines which country appears cheaper. Accordingly if country A is placed in the numerator, the resulting price ratio would reflect it as more expensive than country B, or put differently country B would appear cheaper. 


\section{METHODOLOGY AND RESULTS FOR PRIVATE SECTOR ASSESSMENT}

With the above reservations in mind we now report on two studies that examined prices in South Africa in relation to seven other countries in 1998 and 2001. These studies use the same data source and build on an identical methodology to that of a study first done by Reekie (1997: 20-6). There have been no updates of this latter study since it was first done, and what is presented here is the second of its kind. Without further ado we now proceed with discussing the research carried out but beforehand we describe the sample at hand. The sample of countries compared was South Africa, USA, UK, Germany, Denmark, the Netherlands, Australia, and Brazil. To ensure that the price comparisons are on a like-for-like basis the choice in countries should satisfy three important criteria, namely:

(i) The countries chosen should have relatively liberal drug pricing systems; i.e. price controls on products (particularly on new product introductions) are either absent or exist in limited form, and if the comparisons involve prices of drugs sold for ambulatory care (as is the case here) than these should not be compared with those of drugs sold to bulk-buying institutions or ones with monopsony purchase power. Australia, Brazil and some Southern European states fail on this count in their comparison with the South African private sector. In Brazil, Mendonca (1999) has noted that since the abolition of the pharmaceutical price control system there in 1992 the country's price regime on pharmaceutical products is one of "monitored freedom" where prices are still controlled through voluntary arrangements between the government and the pharmaceutical industry. In Australia the majority of prescriptions are written for medications that are subsidised under the taxpayer funded PBS (Pharmaceutical Benefits Scheme), which grants the Australian government a monopsony purchasing power (OECD, 2001). The prices of all products listed on the PBS are determined and reviewed by the Pharmaceutical Benefits Pricing Authority, which either resorts to reference pricing to infer if a given drug's price is "fair" or includes products in the PBS on the basis of the lowest price or cost (from products falling in the same therapeutic sub-groups).

(ii) Research and Development should play an important part in the market for pharmaceuticals. The OECD (1981) has noted that the South African pharmaceutical industry has a major research and development component and that the country is among the preferred locations of choice for the clinical trial activities of the multination pharmaceutical firms. Reinforcing the strong role of research and development in the industry 
has been the continual or long-standing presence of a strong patent system. All this has been absent from Brazil, which only recently (i.e. as of 1996) placed a formal system in place for the protection of intellectual property rights for pharmaceuticals (Rozek, 2000).

How strong is the enforcement of these rights is questionable. In 1999 a generic law was approved by the Brazilian legislature, which makes it mandatory for the generic name to be included in addition to the trade mark name on all product packs of the original product (Mendonca, 1999).

(iii) The countries should share a corresponding income per capita. In the South African private market, as Table 1 shows, income per capita is in line with that of the high-income category of the World Bank. Thus comparisons with countries, whose income per capita is considerably below that of the South African private sector, as is the case with Brazil or some Southern European states, would be inappropriate.

Table 1 Estimated income per capita for the private sector, 2000

\begin{tabular}{|c|c|}
\hline$\overline{\text { Country }}$ & $\begin{array}{c}\text { Income per capita (in purchasing power } \\
\text { parity), US\$ }\end{array}$ \\
\hline$\overline{\mathrm{USA}}$ & 34100 \\
\hline UK & 23550 \\
\hline Germany & 24920 \\
\hline Denmark & 27250 \\
\hline Netherlands & 24970 \\
\hline Australia & 25850 \\
\hline Brazil & 7300 \\
\hline South Africa ${ }^{1}$ & 36288 \\
\hline High-income group $^{2}$ & 27770 \\
\hline EU & 23600 \\
\hline High-income OECD countries ${ }^{3}$ & 24874 \\
\hline
\end{tabular}

Sources: (1) World Development Report 2002 - World Bank, Oxford University Press.

(2) Registrar of Medical Schemes Annual Report 2000 - Council for Medical Schemes (Pretoria).

Notes: 1 The World Bank's Development Report for 2002 recorded the South African population at 43 million people in 2000 and the South African Gross National Income (in purchasing power parity terms) at US\$ 392 billion in 2000. The Annual Report for 2000 by the Registrar for Medical Schemes records the size of the South African private sector, 
i.e. those with medical aid/insurance, at 7 million in 2000. As per the World Bank's Development Report for 2002 which provides a breakdown of the income share of each income quintile it was assumed that the 7 million people forming the private sector constitute the highest paid 20 per cent of the population, which accounts for 64.8 per cent of the total South African income. The South African figure is an over-estimate. First not all 7 million people are likely to be part of the highest paid 20 per cent of the population, i.e. the possibility of middle income has to be accepted. Accordingly those paying for medical cover may account for less of the total South African income. Second the income per capita calculation assumes the denominator is 7 million people. This is an understatement. People without medical aid/insurance cover also attend private sector health care facilities (e.g. hospitals, doctors, pharmacies) via out-of-pocket expenditure.

2 This group comprises the EU, the high-income OECD countries, and the high-income non-OECD countries. The income per capita for the high-income group is the average for the aforementioned groupings. The income per capita for the EU is also the average for the EU member states. By analogy the same applies for the high-income OECD countries.

3 Income per capita calculation based on data for 21 of the 23 highincome OECD member states.

From the sample selection criteria the following should be taken cognisance of. Although the comparisons with Australia and Brazil (or for that matter these involving some Southern European States like Spain) would not live up to fulfil the sample selection criteria in turn making them questionable, their inclusion for reasons to be detailed later highlights the importance of pricing freedom and strong intellectual property protection.

Let us now see what the studies entailed. The private sector studies looked at how much a basket of some of the best selling products in South Africa would cost in the other seven countries. The list prices of the products, which were in the currencies of each country, are ex-factory prices for ethical, i.e. prescriptionbased, products dispensed through pharmacies. The source of the raw data for these prices (and the corresponding product volumes) is the market research house IMS.

Prices were compared in Rands at the year-end exchange rate for 1998 and 2001. The sample was restricted (owing to data availability) to the top 80 products in South Africa in 1998 and 2001, ranked according to sales value. Of the 80 products, on the average, 23 products were actually found in common to be important sellers in the other countries in 2001 and 18 in 1998. The 
remaining products were either produced only by South African pharmaceutical companies or were products that had ceased to be major sellers in the foreign markets. The prices of the common products, weighted by market share determined from their volumes traded in South Africa, were aggregated to derive a weighted average in order to find out how much the hypothetical basket (of comparable products) would cost in South Africa vis-à-vis the other countries studied. It was assumed when making the calculations that the market shares that the top selling products had in South Africa in 1998 and 2001 would be the same in the other countries as well. Simply put to address the question of how much South African consumers might pay (at ex-factory prices) if they faced foreign prices but maintained South African consumption patterns, prices were weighted according to the volume of purchases by South African consumers. Mathematically the calculations were carried out as per the standard formula for weighted average expenditure (WAE) given below:

$\mathrm{WAE}=\mathrm{S}\left(\mathrm{p}_{\mathrm{i}} \mathrm{q}^{\mathrm{SA}}{ }_{\mathrm{i}}\right) / \mathrm{Sq}^{\mathrm{SA}}{ }_{\mathrm{i}}$

where $S$ is the summation sign over the basket of the common products, $p_{i}$ the price for the $i^{\text {th }}$ product, and $\mathrm{q}^{\mathrm{SA}}$ its quantity consumed in South Africa.

Expression [1] was applied once to take account of the South African prices and a second time to take account of the non-South African prices, with the resulting values used to form the ratios in Table 2 .

Table 2 Eight country comparison -top 80 products

\begin{tabular}{||c|c|c|c|c|c||}
\hline \multicolumn{3}{|c|}{1998} & \multicolumn{3}{c|}{ 2001 } \\
\hline $\begin{array}{c}\text { Pairwise } \\
\text { comparison }\end{array}$ & $N$ & $\begin{array}{c}\text { Price } \\
\text { Ratio }\end{array}$ & $\begin{array}{c}\text { Pairwise } \\
\text { comparison }\end{array}$ & $N$ & $\begin{array}{c}\text { Price } \\
\text { Ratio }\end{array}$ \\
RSA/USA & 21 & $1.00: 4.58$ & RSA/USA & 27 & $1.00: 3.20$ \\
RSA/UK & 22 & $1.00: 1.16$ & RSA/UK & 27 & $1.00: 1.40$ \\
RSA/Germany & 11 & $1.00: 1.06$ & RSA/Germany & 20 & $1.00: 1.19$ \\
RSA/Denmark & 13 & $1.00: 1.12$ & RSA/Denmark & 20 & $1.00: 1.24$ \\
RSA/Netherlands & 21 & $1.00: 1.14$ & RSA/Netherlands & 27 & $1.00: 1.29$ \\
RSA/Australia & 21 & $1.00: 0.83$ & RSA/Australia & 26 & $1.00: 0.79$ \\
RSA/Brazil & 14 & $1.00: 1.17$ & RSA/Brazil & 16 & $1.00: 1.15$ \\
\hline
\end{tabular}

Note: $\mathrm{N}=$ Number of comparable products

A note on interpreting the ratios is in order. The South African value would always be equal to 1 , while the value for the foreign country would be variable. If the foreign country value is greater than 1 , this means that country has higher prices than South Africa for the same basket of goods. The reverse would apply if the foreign country value were below 1. For example, for 2001 the ratio in the 
pairwise comparison RSA/Netherlands is 1.29 . This means that ex-factory prices in the Netherlands are 29 per cent higher than in South Africa (at a point in time) for the same basket of goods available in South Africa and the Netherlands.

\section{ANALYSIS OF PRIVATE SECTOR RESULTS}

There is little to suggest from the studies reported on above that South African private sector prices for pharmaceuticals are far out of line from those of countries with similar degrees of regulation, importance of research and development, and roughly similar income levels. We come to that conclusion, however, in the light of the reservations expressed earlier. What adds credibility and some confidence to the findings here is that they confirm the systematic inability of the evidence to show that the prices of pharmaceuticals in the South African private sector are high in relation to comparable markets. For instance the findings here reinforce (or support) those of the earlier study by Reekie (1997: 25) reported in Table 3 below. It would be recalled that this study is based on the same methodology as the one applied here. The difference is that the top 50 rather than the top 80 products were looked at (also using IMS exfactory list prices data as it applies to ethical drugs dispensed through pharmacies).

\section{Table 3 Six country comparison - top 50 products (1995)}

\begin{tabular}{||c|c|c||}
\hline $\begin{array}{l}\text { Pairwise Country } \\
\text { Comparison }\end{array}$ & $\begin{array}{c}\text { Number of Comparable } \\
\text { Products }\end{array}$ & Price ratio \\
\hline RSA : USA & 20 & $1.00: 1.57$ \\
\hline RSA : UK & 21 & $1.00: 0.75$ \\
\hline RSA : Germany & 15 & $1.00: 1.59$ \\
\hline RSA : Denmark & 19 & $1.00: 1.00$ \\
\hline RSA : Netherlands & 22 & $1.00: 1.16$ \\
\hline
\end{tabular}

Source: Reekie (1997: 25)

It should be noted that direct comparison of the price ratios between Table 2 and Table 3 (and within Table 2 itself) is not possible since the products between the periods are not the same, i.e. new products are introduced and old ones are discontinued over time. All that can be inferred is that at any point in time the comparable basket of important sellers across the comparable countries examined costs less in South Africa than elsewhere. For instance in 2001, for directly comparable products, relative to South African prices US prices were 220 per cent higher, UK prices were 40 per cent higher, German prices 19 per cent higher, Danish prices 24 per cent higher, and for the Netherlands 29 per 
cent higher. In the sample of comparable markets (countries) considered in Table 2 (and Table 3) South Africa consistently appears to be the second cheapest country whilst the USA was always the most expensive.

Although direct price comparisons with Australia and Brazil may not be possible, their comparison to the South African private sector highlights two important points, namely:

(a) where intellectual property protection is perverted relative to en environment where it is not prices of pharmaceutical products are higher. In this case they were 15 per cent higher in 2001 and at least this much in 1998; and

(b) Free markets produce prices, which are as low, and very likely lower compared to ones arrived at by government control or intervention. In cases where such controls or interventions exist the cost(s) they come with must also be examined. Although Australian prices may be around 20 per cent lower than South African ones (whether in 1998 or 2001), 84 per cent of the total cost of the PBS is subsidised by government (OECD, 2001: 155).

The evidence suggests that letting freedom of choice in the selection of products exist and allowing manufacturers to exercise discretion in the pricing of their products, subject to their assessment of the conditions of demand and supply, produces the results that legislative proposals in the name of the public interest, like parallel trade, promise to attain.

A detailed report by the Boston Consulting Group, which studied the impact of price controls on pharmaceuticals, came to a conclusion not dissimilar to the one expressed above. In particular the report (1999: 36) noted that "the diffusion of innovation seems to bear out a simple economic truth: where pharmaceutical companies have an economic incentive to ensure that more people get treated, and are given the freedom to price and market accordingly in response to market competition, more people will get appropriately treated. Where these incentives and freedoms are reduced, treatment levels reflect the policies put in place by the government officials who define pharmaceutical industrial policy".

At this point we move to the pricing study for the public sector.

\section{METHODOLOGY AND RESULTS FOR PUBLIC SECTOR STUDY}

Following various allegations of excessive pricing in South Africa compared to international sources, as described in Report 6 of 1997 by the Public Protector, an analysis was undertaken of prices in the South African State sector. The 
government bases its purchases on pharmaceuticals on nine tenders. Out of the nine tenders, information pertaining to only eight of these could be obtained.

In all cases the price comparisons were based on the weighted volumes of the quantities (in packs) called for on the COMED tenders. The intention is to show what the total purchase value would be on a weighted basis as opposed to price alone. Simply put to maintain consistency with the methodology followed on the private sector studies, inter alia, use is made of expression [1] in the case of the public sector too. Here to address the question of how much the South African State might pay if it faced foreign prices but maintained its consumption patterns, prices were weighted according to the volume of purchases the State makes.

The public sector price comparison involves (a) low levels of income (see Table 4) and (b) the same kind of pharmaceuticals, i.e. generics.

Table 4 Estimated Income Per Capita For The Public Sector, 2000

\begin{tabular}{|c|c||}
\hline Country & $\begin{array}{c}\text { Income per Capita (in Purchasing } \\
\text { Power Parity), US\$ }\end{array}$ \\
\hline South Africa & 316 \\
Low-Income Countries & 1980 \\
\hline
\end{tabular}

Sources: (1) World Development Report 2002 - World Bank, Oxford University Press.

(2) Registrar of Medical Schemes Annual Report 2000 - Council for Medical Schemes (Pretoria).

Note: ${ }^{1}$ The World Bank's Development Report for 2002 recorded the South African population at 43 million people in 2000 and the South African Gross National Income (in purchasing power parity terms) at US\$ 392 billion in 2000. The Annual Report for 2000 by the Registrar for Medical Schemes records the size of the South African private sector, i.e. those with medical aid/insurance, at 7 million in 2000. Thus it was assumed the public sector takes care of 36 million people. As per the World Bank's Development Report for 2002 which provides a breakdown of the income share of each income quintile it was assumed that the 36 million people forming the public sector constitute the lowest paid 20 per cent of the population, which accounts for 2.9 per cent of the total South African income. The South African public sector figure is an under-estimate. First not all 36 million people are likely to be part of the lowest paid 20 per cent of the population, i.e. the possibility of middle income has to be accepted. Accordingly those using public sector health facilities may account for more of the total South African income. Second the income per capita calculation assumes the denominator is 36 
million people. This is an overstatement. People without medical aid/insurance cover also attend private sector health care facilities (e.g. hospitals, doctors, pharmacies) via out-of-pocket expenditure.

The public sector comparison was conducted using the International Drug Price Indicator Guide (IDPIG) jointly developed by the World Health Organisation and Management Sciences for Health (a non-profit organisation). The guide is an indicator of the international price norm of generics. It is appealing to use because it provides the actual international tender prices through international competitive bidding (ICB) for the supply of generic drugs by procurement agencies and vendors to poor or low-income countries.

In summary the international price comparison for the public sector refers to prices that are (a) obtained through a tender based process, (b) are aimed at the same income level and (c) involve the same kind of drugs. The data comprises list prices. The comparison is with reference to available data for the year 2000 .

To ensure the comparison is on a like-for-like basis the international and COMED tender prices refer to products common to the South African essential drug list, the COMED tenders, and the listing of products obtainable through international competitive bidding. In total 79 comparable products were identified. Of the 79 products considered information on 71 was available. The products came from the various tenders as depicted in Table 5.

\section{Table 5 Composition of public sector price comparison sample}

\begin{tabular}{||l|c||}
\hline Tenders & $\begin{array}{c}\text { Tender origin of } \\
\text { products (\%) }\end{array}$ \\
\hline RT 280 - Drops, Aerosols, Inhalers and Inhalants & 4 \\
\hline RT 281 - Semi-Solids and Powders & 4 \\
\hline RT 285 - Biological Preparations & 1 \\
\hline RT 289 - Solid Dosage Forms & 21 \\
\hline $\begin{array}{l}\text { RT 297 - Small Volume Parenterals and Insulin } \\
\text { Administration Devices }\end{array}$ & 1 \\
\hline RT 299 - Large Volume Parenterals and Accessories & 4 \\
\hline RT 300 - Liquids & 9 \\
\hline RT 301 - Antibiotics & $\mathbf{1 0 0}$ \\
\hline TOTAL & \\
\hline
\end{tabular}

Source: Office of the State Tender Board - Tender contracts

Data from the products considered reveals that in the case of the COMED tenders 71 per cent of products are supplied in patient-ready packs and 29 per 
cent in bulk packs. In short under the COMED tenders the prices for products apply to packs. By contrast the prices for products obtainable through international competitive bidding are exclusive of packaging and recorded in comparable dosage unit (e.g. tablets or millilitres). Like the COMED tender prices the international tender prices are delivery or CIF (cost, insurance, and freight) inclusive. In contrast to the COMED tender prices the international tender prices are not VAT inclusive. To make the comparison in the same currency the year-end Rand-Dollar exchange rate for 2000 was applied (given international tender prices are recorded in US dollars). In addition to account for the difference in packaging and VAT the international tender prices in each instance (prior to calculating the expenditures) were loaded by:

(a) The size of the pack required under the COMED tender.

(b) 10 per cent to reflect the cost of packaging (on the premise, following a study by the NPI (1989, p 53-64), that packaging costs for South African pharmaceutical manufactures amount to 10 per cent of total manufacturing costs, and that these costs are the same for the international suppliers); and

(c) 14 per cent to reflect the presence of VAT.

In all cases the price comparisons were based on the estimated quantities (in packs) called for on the COMED tenders. Table 6 presents the price comparison result (with expression [1] being applied on the one occasion to take account of the South African prices and on the other of the non-South African prices, with the values so formed used to obtain the ratios in the table. The interpretation of the ratios is the same as that for Table 2. For instance in 2000, for directly comparable products, relative to COMED prices, IDPIG prices were 53 per cent higher. Put another way relative to the IDPIG international tender prices, prices obtained under the COMED tender system yield the State a 53 per cent saving in its drug expenditure (for comparable products).

Table 6 Comed-IDPIG comparison for 71 common products, 2000

\begin{tabular}{|l|c||}
\hline & Price ratio \\
\hline For COMED Tenders at Comed Prices & 1.00 \\
\hline $\begin{array}{l}\text { For COMED Tenders at International (IDPIG) Tender } \\
\text { Prices }\end{array}$ & 1.53 \\
\hline Savings & $53 \%$ \\
\hline
\end{tabular}

Note: The information is based on 8 out of 9 tenders in total 


\section{ANALYSIS OF PUBLIC SECTOR RESULTS}

There is little to suggest from the above study that the South African public sector prices for pharmaceuticals, the State secures through the COMED tender system, are higher than the international tender prices the State would face if it were to participate in international competitive bidding for the same drugs. Relative to the IDPIG international tender prices, prices obtained under the COMED tender system yield the State a 53 per cent saving in its drug expenditure (for comparable products). In short it appears that the competitionfor-the-market the COMED tender system creates in the supply of drugs for the public sector is very intense compared to the ICB norm. What adds credibility and some confidence to the findings here is that they join a list of studies that systematically fail to show that the prices of pharmaceuticals in the South African public sector are high when compared with the IDPIG norm. The previous studies (PMA, 2001: 28), which are based on comparisons involving the average of IDPIG supplier rather than tender prices, have established that the savings in expenditure achieved by the State with the use of COMED (relative to the IDPIG) could be deemed to be 30 per cent on the average.

In the present study it should be accepted that the saving is likely to be lower than estimated. First as presented above there are historical reasons for supposing so. In addition in the case of the public sector study assumptions were made in order to balance off the packaging difference between the COMED and international tender prices. If the packaging cost for the international suppliers is lower than the one assumed than the reported savings would also be lower. It should also be noted that quantity estimates rather than actual consumption figures were available for the calculation of the expenditure figures. Any discrepancies between the estimates and the actual figures (which must be assumed exist) would also mean that we have to content with accepting a level of savings lower than is reported in Table 6.

\section{CONCLUSION}

On the basis of the findings the conclusion drawn is simple. The results provide little support for the view that South African prices are in need of controls over and above those already existing through competition, i.e. recall that in the private sector companies are free to price their products and that in the public sector competition is encouraged by means of tendering. The evidence reveals that any calls or public policy proposals for parallel importation and its variant reference pricing are misplaced. To put forward such proposals without taking account of existing empirical knowledge for policy (or legislative) making 
purposes is a less than optimal approach and one that the South African legislature ought to steer away from.

\section{ENDNOTES}

1 I would like to thank the head office of a PMA member company, without whose help it would not have been possible to gain access to the proprietary IMS raw data on which the private sector studies are based. I would also like to thank Ms Marita van Rooyen from the Pharmaceutical Management Cluster of the Department of Health for providing the proprietary COMED data pertaining to the quantity estimates for the public sector without which conducting the public sector study would not have been possible. Thanks are due to Prof. WD Reekie for spending time to elaborate on his pricing studies on the pharmaceutical industry. The assistance of Ms Christine Schoeman during the data processing stages of the studies reported in here is acknowledged. The views expressed by the author (in this article) do not represent those of the Pharmaceutical Manufacturers' Association of South Africa.

2 Generic medicine is the one with the same chemical composition or active ingredient as the original medicine.

\section{REFERENCES}

1 BOSTON CONSULTING GROUP (1999) Ensuring Cost-Effective Access to Innovative Pharmaceuticals - Do Market Interventions Work?, Boston, USA.

2 DANZON, P.M. (2000) "Making sense of drug prices", Regulation, 23(1): 56-63.

3 MENDONCA, T. (1999) "Report on the Brazilian pharmaceutical industry" Report by the U.S. Foreign Commercial Service and U.S. Department of State, Washington, USA.

4 MANAGEMENT SCIENCES FOR HEALTH (2001) International Drug Price Indicator Guide 2000, Arlington (VA), USA.

5 NESBITT, E.R. (2000) "Pricing of prescription drugs" Report by the U.S. International Trade Commission, Washington, USA.

$6 \quad$ NATIONAL PRODUCTIVITY INSTITUTE (1989) Productivity Study of the Pharmaceutical Manufacturing Industry in South Africa, Pretoria, South Africa.

7 ORGANISATION FOR ECONOMIC CO-OPERATION AND DEVELOPMENT (1981) Multinational Enterprises, Governments and Technology: The Pharmaceutical Industry, Paris, France. 
8 (2001) Competition and Regulation Issues in the Pharmaceutical Industry, Paris, France.

9 PHARMACEUTICAL MANUFACTURERS' ASSOCIATION (2001) Annual Report 2001, Johannesburg, South Africa.

10 PUBLIC PROTECTOR (1997) Report 6: Report on the Propriety of the Conduct of Members of the Ministry and Department of Health Relating to Statements in Connection with the Prices of Medicines and Utilisation of Generic Medicines in South Africa, Pretoria, South Africa.

11 REEKIE, W.D. (1984) "Drug prices in the UK, USA, Europe and Australia", Australian Economic Papers, 23(2): 71-78.

12 (1997) “The PPRS: Regulations without a cause?", in: Green, D.G. (ed.) Should Pharmaceutical Prices be Regulated?, IEA Health and Welfare Unit, London, UK.

13 ROZEK, R.P. (2000) "The effects of compulsory licensing on innovation and access to healthcare" Report by National Economic Research Associates (NERA), Washington, USA.

14 SOUTH AFRICA (1997) "Medicines and related substances control amendment act" Act 90, Government Gazette No 18505, Government Printers, Pretoria. 